ПЕШКОВА Вера Михайловна - кандидат исторических наук, старший научный сотрудник Института социологии Федерального научно-исследовательского социологического иентра РАН (117218, Россия, г. Москва, ул. Кржижановского, 24/35 корп. 5; pever@таil.ru)

\title{
ОБЩЕСТВЕННЫЕ АКТИВИСТЫ О ПРОБЛЕМАХ И ПЕРСПЕКТИВАХ РАЗВИТИЯ НКО И МЕСТНЫХ СООБЩЕСТВ В МАЛОМ РОССИЙСКОМ ГОРОДЕ
}

\begin{abstract}
Аннотация. В статье рассматривается отношение общественных активистов к проблемам и перспективам развития некоммерческих объединений и местных сообществ в малых городах. Автор основывается на анализе материалов комплексного социологического обследования, проведенного в 2019 г. в 16 типичных малых российских городах. В статье показываются особенности активности общественных объединений в малых городах; выявляются как общие, так и специфические проблемы, характерные для активности НКО и развития местных сообществ. Среди последних автор выделяет зависимость от внешних источников финансирования; ограниченные возможности финансирования в малых городах; процедурные и налоговые сложности при создании и деятельности объединения в качестве юридического лица; слабую координацию либо ее отсутствие в работе объединений. В заключение дается оценка места и роли НКО, а также конкретные предложения относительно перспектив развития общественных объединений и местных сообществ в целом.
\end{abstract}

Ключевые слова: малый город, местные сообщества, пространственное развитие, общественные активисты, некоммерческие объединения

Современные вызовы развитию России имеют пространственно-территориальные аспекты. Их актуальность находит отражение в Стратегии государственной политики в отношении пространственного развития российских территорий ${ }^{1}$, в т.ч. малых городов, где проживает около $12 \%$ населения страны. Наиболее острыми из проблем малых городов принято считать безработицу, закрытие или сокращение градообразующих предприятий, специализацию рынка труда, снижение качества жизни, отток населения, маргинализацию населения (особенно молодежи), кризис социальной идентификации горожан и обветшание городской инфраструктуры [Малые города... 2014; Малые города в социальном... 2019].

Помимо Стратегии пространственного развития, комплекс мер по решению данных проблем предусмотрен и национальными приоритетными проектами, в реализацию которых предусматривается включать жителей городов 2 . Внимание к местным сообществам также объясняется тем, что их развитие связывают, во-первых, с углублением понимания темы местного самоуправления [Демчук 2019; Шаронин 2009], во-вторых, с изучением гражданского общества [Пясецкая 2015; Галкина 2007; Киселева 2007]. Местные сообщества, как правило, формируются вокруг общественных активистов и институтов, прежде всего некоммерческих объединений [Климова, Щербакова 2015; Мерсиянова,

\footnotetext{
1 Послание Президента РФ Федеральному собранию от 01.03.2018 и от 20.02.2019 г; Указ Президента РФ от 07.05.2018 № 204 «О национальных целях и стратегических задачах развития Российской Федерации на период до 2024 г.».

2 Например, приоритетный проект «Формирование комфортной городской среды». Доступ: http://government.ru/projects/selection/649/ (проверено 03.11.2020); Всероссийский конкурс лучших проектов создания комфортной городской среды в малых городах и исторических поселениях http://government.ru/awards/698/about/ (проверено 03.11.2020).
} 
Якобсон 2007]. В связи с этим изучение отношения общественных активистов к проблемам и перспективам развития НКО и местных сообществ в малых городах приобретает актуальность.

Статья основывается на анализе материалов комплексного социологического исследования, проведенного в 2019 г. сотрудниками и региональными коллегами Института социологии ФНИСЦ РАН. Обследование проведено в 16 типичных российских городах с численностью до 50 тыс. жителей, отобранных с учетом регионально-пространственных факторов. В восьми федеральных округах взяты по два малых города - входящий и не входящий в агломерацию крупного города: Лихославль и Кимры (Тверская обл.), Сокол и Красавино (Вологодская обл.), Аксай и Миллерово (Ростовская обл.), Изобильный и Новоалександровск (Ставропольский край), Балахна и Заволжье (Нижегородская обл.), Среднеуральск и Ирбит (Свердловская обл.), Шелехов и Зима (Иркутская обл.) и Большой Камень и Спасск-Дальний (Приморский край). В каждом городе проведены фокус-группы (16 фокус-групп) и экспертные интервью (16 интервью) с представителями местных НКО.

Общественные объединения обследуемых малых городов, как правило, охватывают разные сферы интересов местных жителей и включают такие тематические направления деятельности, как ветеранское, молодежное, образовательное, этнокультурное, историческое патриотическое, спортивное, инвалидное, детское, женское и т.п. В каждом городе существует несколько десятков зарегистрированных организаций. Кроме того, поскольку в малом городе частота и плотность контактов достаточно высоки, деятельность общественных организаций зачастую не ограничивается заявленной в уставе, а принимает, по выражению участников фокус-групп, форму социальной и соседской помощи.

При анализе деятельности общественных объединений и местных сообществ в малом городе также следует иметь в виду, что большинство активистов являются уроженцами города, т.е. «все родственники, все знакомы, все соседи» (ФГ, г. Сокол). Это значит, что при взаимодействии заинтересованных сторон огромную роль играют личные связи, что, с одной стороны, усложняет их взаимодействие при решении некоторых вопросов, с другой - упрощает.

По мнению активистов, развитие общественных объединений и сообществ следует рассматривать не только в контексте социально-экономического состояния малого города, но и шире - региона и страны в целом. Анализ экспертного мнения и оценок участников фокус-групп выявляет рейтинг актуальных для обследуемых городов проблем:

1) социальные (уровень и качество медицинских и образовательных услуг, социальное обеспечение, льготы);

2) состояние ЖКХ (жилье, высокие тарифы, политика управляющих компаний);

3) занятость населения (отъезд квалифицированных специалистов и молодежи, низкие заработные платы, отсутствие промышленных предприятий);

4) состояние городской среды;

5) современная федеральная бюджетная политика в отношении малых городов (перераспределение налогов через региональные бюджеты, собственники крупных предприятий не платят налоги в местный бюджет, финансирование по остаточному принципу и недофинансирование);

6) состояние малого и среднего предпринимательства;

7) нерешенные последствия диверсификации экономики моногородов.

Поскольку активность общественных объединений в значительной степени зависит от внешних источников, одним из самых главных и даже более 
болезненных, чем для других участников городского сообщества, вопросов на протяжении многих лет является вопрос финансирования. Первый источник финансирования - местный бюджет. Отмечая положительные изменения в работе городских властей, большинство активистов считают, что местная власть обладает очень ограниченными финансовыми и административными ресурсами. Это снижает уровень ожиданий относительно возможностей муниципальных властей решать проблемы города, включая проблемы общественных объединений: «у города своих проблем куча, в администрации, каждый выживает как может» (ФГ, г. Изобильный). Более позитивно оценивают условия своей активности представители общественных организаций в моногородах. Объясняется это тем, что в малых моногородах крупные промышленные предприятия берут на себя финансовую и административную помощь своим, ведомственным (например, ветеранским) общественным организациям.

Наиболее заметным механизмом взаимодействия местных властей и населения городов являются различные целевые государственные программы. Но одно из условий участия в них состоит в софинансировании. Особенно остро эта проблема встает при реализации программ поддержки местных инициатив, предполагающих участие населения, чей уровень жизни и, следовательно, возможности инвестиций во многих малых городах являются очень ограниченными.

В то же время именно программы местных инициатив оцениваются активистами как одни из самых эффективных и перспективных государственных программ, поскольку стимулируют развитие городского самоуправления и воспитывают в населении ответственное отношение к реализации проектов и дальнейшей эксплуатации создаваемых в их рамках объектов. «Если это строится с участием жителей, или с участием хотя бы какой-то части средств или вложений жителей, то объект функционирует, как правило, дольше и с меньшими потерями. Если жители изначально в этом участвовали, то потом оно и содержится соответствующим образом лучше. Понятно, влияет на положение дел населенного пункта» (ФГ, г. Миллерово).

Отсутствие или незначительные собственные источники финансирования также играют роль и при участии общественных объединений в различных региональных и федеральных грантовых конкурсах. По мнению городских активистов, хотя гранты позволяют участвовать в федеральных конкурсах напрямую, что повышает вероятность целевой помощи, но не у всех общественных организаций есть финансовые и интеллектуальные ресурсы для того, чтобы хотя бы принять участие в конкурсе. Другие факторы, останавливающие общественные организации, - сложность оформления документов, высокая конкуренция, непрозрачность подведения итогов, а также то, что размер гранта не оказывает решающего влияния на деятельность организации.

Ограниченные возможности финансирования многие городские власти стараются компенсировать с помощью административного ресурса. Поэтому не удивительно, что одним из критериев оценки взаимодействия объединений и местной администрации, состояния общественного сектора малого города в целом является то, насколько активно городская власть оказывает организационную помощь, выделяет транспорт и помещения, выступает посредником между объединениями и предпринимателями. При этом важна степень доступности администрации при решении вопросов, когда «не обязательно писать километры писем, дозваниваться и т.д., а инициативы поддерживаются максимально» (ФГ, г. Спасск-Дальний). Положительно оценивается и то, насколько регулярно глава города и руководители профильных отделов 
собирают представителей организаций для обмена информацией и решения совместных вопросов.

Вторым источником финансирования общественного сектора и участником городского взаимодействия являются местные предприниматели, некоторые из которых также входят в состав организаций и финансируют их деятельность. Но большая часть опрошенных активистов оценивают помощь со стороны предпринимателей как благотворительность или как помощь нуждающимся. Они единодушны в признании роли предпринимателей, но также отмечают ограниченность и этого ресурса. Дело в том, что большая часть местного бизнес-сообщества представлена индивидуальными и малыми предпринимателями. Кроме того, в малом городе число подобных предпринимателей меньше, чем в более крупном городе. Вот что об этом говорят участники фокус-групп: «...я пришла к [фамилия предпринимателей] ...она говорит: “Вот три организации, как мне дать, чтобы Вас никого не обидеть. Всем дам по одной тысяче, чтоб никому не было обидно”. А чего на тысячу-то проведешь?» (ФГ, г. Красавино).

По мнению участников фокус-групп, взаимодействие между представителями местных сообществ и предпринимателями может стать более эффективным только после принятия соответствующих решений на общероссийском уровне. Предлагается разработать закон, благодаря которому социально ответственный бизнес, в т.ч. оказывающий помощь общественным объединениям, получает налоговые льготы либо другие преимущества. Крупные предприятия и торговые сети должны делать отчисления в местный бюджет, в т.ч. на помощь сообществам: «обязать магазины, ...фирмы Москва и Питер, чтобы они несли ответственность и за состояние прилегающей территории, ...на какой территории вы делаете деньги - там ответственность несете» (ФГ, г. Красавино).

Помимо общей для многих местных сообществ проблемы с источниками финансирования, участники обследования называют специфические, характерные только для общественных объединений проблемы. Одна из них необходимость осуществлять деятельность через создание юридического лица, что, вместо облегчения работы общественных организаций, усложняет ее, в частности, влечет дополнительные расходы и налоговую нагрузку, а также сопровождается громоздкими отчетными процедурами. Общественные активисты единодушны в том, что регистрация НКО - «это большие затраты, и особенно в малых городах» (ФГ, г. Миллерово), поэтому «проще не регистрироваться» (ФГ, г. Шелехов). В связи с этим представители НКО предлагают, во-первых, упростить бухгалтерскую отчетность, во-вторых, пересмотреть правила налогового обложения зарегистрированных как юридические лица некоммерческих объединений, которые не могут и не должны нести такую же налоговую нагрузку, как бизнес. Конфликтность ситуации ярко описал один из участников фокус-группы: «...скажу о ДОСАФ: плачу полностью налоги, как будто на рынке стою... и я еще должен заниматься патриотикой в районе» (ФГ, г. Изобильный).

Другой проблемой является слабая координация либо отсутствие координации активности различных общественных объединений. Одна из причин разобщенности - конкуренция за ресурсы (финансовая и административная помощь городских властей, спонсорская помощь), вторая - разный символический, материальный и человеческий капитал собственно самих некоммерческих организаций. Причем положение объединений в малых городах, по мнению местных активистов, усугубляется тем, что из-за существующей политики перераспределения ресурсов из районного или областного центра 
до НКО малых городов доходит денег меньше, чем в районные и областные организации.

Несмотря на проблемы, активисты высоко оценивают роль общественных объединений в развитии местных сообществ и малого города в целом. Во-первых, НКО представляют городское сообщество во взаимодействии с муниципальными властями и предпринимателями. Иными словами, они являются посредниками между населением и остальными участниками городского взаимодействия и знают «на какие рычаги нажимать» (ФГ, г. Зима). Тем самым НКО помогают решать важные социальные вопросы, актуальные для большей части не вовлеченных в активную общественную деятельность горожан. Во-вторых, общественные объединения малых городов эффективнее, чем объединения в крупных городах, сплачивают население, формируют собственно городское сообщество, которое умеет формулировать свои интересы и потребности, представлять их заинтересованным сторонам и принимать участие в решении этих вопросов. Как выразился один из участников фокус-групп, «любое общественное объединение - маленький кирпичик во всем строении. Вместе с ними и получается, что мы имеем на сегодня неплохой город, неплохое настроение людей, ...в целом получается большое сообщество» (ФГ, г. Лихославль). Наконец, некоммерческие объединения участвуют в формировании имиджа города, причем не только на районном, областном, но и на федеральном уровне.

Отмечая большую роль НКО в малом городе, их представители считают активность и уровень согласованности деятельности различных общественных организаций только одним из показателей развития гражданского сообщества. В отношении такого показателя, как высокая социальная активность всего населения города, участники фокус-групп менее оптимистичны. Низкая социальная активность объясняется как общим снижением уровня жизни населения всей страны, апатией по отношению к общественным вопросам, так и характерными именно для малых городов проблемами. В то же время, когда возникает ситуация, затрагивающая, согласно активистам, жизненно важные интересы всех жителей города, население быстро мобилизуется и объединяется. Примеры этому - митинги против закрытия завода в г. Новоалександровске, против «мусорной» реформы или против строительства низконапорного гидроузла в Нижегородской обл.

Как активисты и эксперты видят перспективы развития общественных объединений и в целом местных сообществ в своем малом городе? Прежде всего они определяются перспективами не только малого города, но региона и страны в целом, а именно уровнем социально-экономического развития, уровнем и качеством жизни населения. Последнее особенно актуально для малых городов. Малый город должен быть городом, комфортным для жизни. Разрыв в уровне жизни населения малого и большого города предлагается уменьшить в первую очередь через развитие городской инфраструктуры: спортивной, культурной, досугово-развлекательной, социальной и т.п. Это, как правило, более важно для жителей городов, не входящих в агломерации, поскольку городаспутники часто имеют достаточно хороший транспортный доступ к инфраструктуре крупного города.

Федеральную власть призывают принципиально поменять экономическую модель: создать условия, чтобы местные органы власти имели больше полномочий для собственного обеспечения своего города. Помимо этого, по мнению активистов, наличие в городе хотя бы одного крупного промышленного предприятия внесет своей вклад в решение таких вопросов, как создание рабочих мест, поддержка социальной, развлекательной и транспортной инфраструк- 
туры, снижение налоговой нагрузки на малый и средний бизнес, продвижение имиджа города.

Что касается специальных условий для деятельности НКО, здесь предлагается:

- пересмотреть налогообложение и процедуру отчетности для организаций со статусом юридического лица;

- поощрять спонсорскую активность как местных малых и средних предпринимателей, так и крупных федеральных предприятий и торговых сетей;

- пересмотреть существующую практику распределения денег на общественную активность из области;

- работать над улучшением координации работы разных некоммерческих объединений, в т.ч. через общественные советы.

Наконец, возможно, наступило время пересмотреть принцип деятельности общественных объединений в целом, особенно в малых городах, чтобы уйти от формата работы «выживания на энтузиазме».

\section{Список литературы}

Галкина Е.В. 2007. Местное самоуправление и гражданское общество в современной России: проблемы функционирования. - Социология власти. № 1. С. 87-96.

Демчук Н.В. 2019. Местное сообщество: интерпретация понятия. - Вестник Майкопского государственного технологического университета. № 2. С. 111-121.

Киселева А.М. 2007. Местное сообщество как основа формирования гражданского общества в России. - Вестник ОмГУ. Сер. Экономика. № 1. С. 64-68.

Климова С.Г., Щербакова И.В. 2015. Опыт изучения территориального контекста гражданского участия. - Мониторинг общественного мнения: экономические и социальные перемены. № 3. С. 12-28.

Малые города - большие проблемы. Социальная антропология малогогорода: сборник статей (под ред. М.Е. Кабицкого, О.Ю. Артемовой, М.Ю. Мартыновой). 2014. М.: Изд-во ИЭА РАН. 358 с.

Малые города в социальном пространстве России: монография (отв. ред. В.В. Маркин, М.Ф. Черныш; предисл. М.К. Горшкова). 2019. М.: Изд-во ФНИСЦ РАН. 545 с.

Мерсиянова И.В., Якобсон Л.И. 2007. Негосударственные некоммерческие организации: институциональная среда и эффективность деятельности. М.: ИД ГУ-ВШЭ. 170 с.

Пясецкая Е.Н. 2015. Местное сообщество и муниципальное управление: трансформация взаимодействия. - Конщепт. № 9. С. 61-65.

Шаронин О.С. 2009. Аспекты институционализации местного сообщества в системе управления малого северного города. - Вестник КГУим. Н.А. Некрасова. № 1. С. 183-188. 
PESHKOVA Vera Mikhailovna, Cand.Sci. (Hist.), Senior Researcher at the Sociological Institute - Branch of the Federal Center of Theoretical and Applied Sociology, Russian Academy of Sciences (bld. 5, 24/35 Krzhizhanovskogo St, Moscow, Russia,117218; pever@mail.ru)

\section{OPINIONS OF THE PUBLIC ACTIVISTS ABOUT THE PROBLEMS AND PROSPECTS OF DEVELOPMENT OF NGOs AND LOCAL COMMUNITIES IN A SMALL RUSSIAN CITY}

Abstract. The article examines the attitude of public activists to the problems and prospects of the development of non-profit associations and the local communities in small-sized towns. The paper bases on an analysis of a comparative sociological investigation, realized in 2019 in 16 typical small Russian cities. The author shows the features of the public associations' activity in small-sized towns and identifies both general and specific problems characteristic of the activity of NGOs and the development of local communities. Among the latter are the dependence on external sources of financing; limited funding opportunities in small towns; procedural and tax difficulties when creating and operating as a legal entity; weak or lack of coordination in the work of associations. In conclusion, the author gives an assessment of the place and role of public associations, as well as specific proposals regarding the prospects for the development of public associations and local communities in general.

Keywords: small-sized town, local communities, spatial development, social activists, non-profit associations

EВСЕЕВА Мария Андреевна - младший научный сотрудник Центра исследования межнациональных отношений Института социологии ФНИСЦ РАН (117218, Россия, г. Москва, ул. Кржижановского, 24/35, корп. 5; m.a.evseeva@mail.ru)

\section{ИДЕИ ОБЩЕРОССИЙСКОЙ ГРАЖДАНСКОЙ ИДЕНТИЧНОСТИ В ПОСЛАНИЯХ ПРЕЗИДЕНТА РФ ФЕДЕРАЛЬНОМУ СОБРАНИЮ: ПОИСК КОНСЕНСУСА}

Аннотация. В статье раскрываются основные идеологемы общероссийской гражданской идентичности в посланиях Президента РФ Федеральному собранию в 2013-2020 гг. Автор рассматривает основные содержательные составляющие общероссийской гражданской идентичности.

Ключевые слова: общероссийская гражданская идентичность, послания Президента РФ, Стратегия государственной национальной политики, российская нация, межнациональные отношения, межнациональное (межэтническое) согласие

$\mathrm{H}$ едавнее голосование по поправкам в Конституцию показало не только достаточно высокий уровень консолидации общества, но и разнообразие по регионам. В связи с этим необходимо раскрыть основные идеологемы общероссийской гражданской идентичности в дискурсе президента РФ.

Идеи М. Вебера о коллективныхпредставлениях, убеждениях, ценностях дают основания для понимания осознаваемой идентичности. Он заложил основы нормативно-ценностной концепции, которая концентрирует внимание на культурном взаимодействии групп, сближении их ценностей и выработке еди- 